\title{
Pseudotumoral tuberculosis of the esophagus
}

\section{J RUBIÉS-PRAT, J SOLER-AMIGÓ, AND C PLANS}

From the Department of Internal Medicine, Ciudad Sanitaria de la Seguridad Social, Universidad Autónoma, Barcelona, Spain

Tuberculosis of the oesophagus without evidence of pulmonary involvement is rare. The purpose of this paper is to report the clinical and radiological findings in a patient with pseudotumoral tuberculosis of the oesophagus probably resulting from unrecognised tuberculous lymphadenitis in the mediastinum.

\section{Case report}

A woman, aged 68, was admitted to hospital in August 1976 because of dysphagia, malaise, loss of weight, and a slightly raised temperature in the late afternoon over a period of two months. She was weak. Her temperature was $37.7^{\circ} \mathrm{C}$. The haemoglobin was $7.8 \mathrm{~g} / \mathrm{dl}$, haematocrit $25 \%$, and white cell count $5.6 \times 10^{\circ} / 1$ with a normal differential count. The ESR was $80 \mathrm{~mm}$ in one hour (Westergren) and the platelet count $230 \times$ $10^{\circ} / 1$. The red cells were hypochromic and microcytic. The serum iron concentration was $4 \mu \mathrm{mol} / 1$. Tests for occult blood in the stools were negative. A tuberculin skin test (10 TU of PPD) was positive $8 \mathrm{~mm}$.

A chest radiograph showed no abnormalities. A barium swallow showed a filling defect in the upper third of the oesophagus (fig 1). Fibreoptic endoscopy was performed on two occasions. A submucosal mass with superficial erosions was found. Histopathological examination of several biopsy specimens showed nonspecific inflammatory changes. The patient was discharged with a diagnosis of sideropenic anaemia and probable leiomyoma of the oesophagus. Iron treatment was started, and the patient was followed up as an outpatient.

In May 1977 the dysphagia disappeared but constitutional symptoms persisted. In July 1977 she was readmitted to hospital with lymph node enlargement in the right supraclavicular fossa. A gland biopsy showed epithelioid cell granulomata with giant cells and caseation. Two days after admission the patient developed chest pain and her temperature rose to $39^{\circ} \mathrm{C}$. A chest radiograph showed a left pleural effusion. The pleural fluid was an exudate with $80 \%$ lymphocytes. A tuberculin skin test (10 TU of PPD) was positive $20 \mathrm{~mm}$. A further barium swallow and oesophagoscopy failed to show the mass that had been seen previously, but there was now an ulcer at the site of the pseudotumour (fig 2). No acid-fast bacilli were found on microscopic examination of gastric washings but $M y$ cobacterium tuberculosis was cultured on LöwensteinJensen medium. Treatment with isoniazid, rifampicin, and ethambutol was started. Because of nausea,

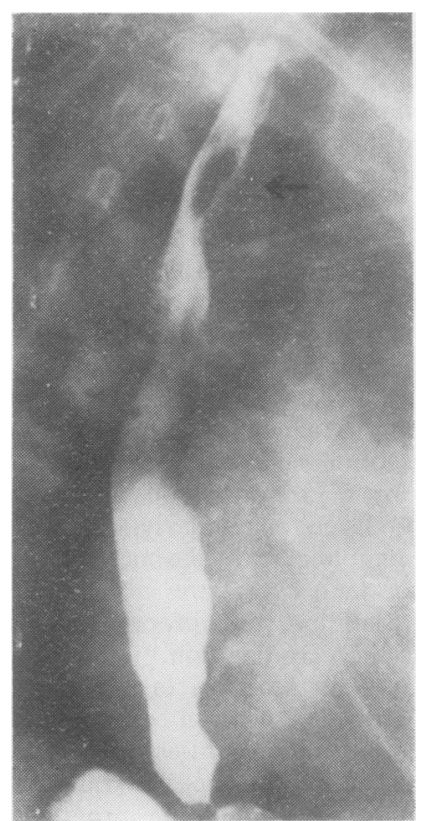

Fig 1 Barium swallow showing a filling defect (pseudotumour) in upper third of oesophagus, August 1976.

jaundice, and raised transaminase levels, rifampicin was discontinued and streptomycin substituted. The fever subsided and the patient's general condition improved with rapid gain in weight.

In November 1977 the patient's general health was good. Her chest radiograph was normal. A barium N swallow showed some irregularity of the oesophagus $\delta$ and traction diverticula (fig 3). At oesophagoscopy a $N$ healed ulcer was seen suggesting that a caseous gland $N$ mass in the mediastinum had discharged its contents into the oesophagus. In 1979 the patient remains asymptomatic.

\section{Discussion}

Tuberculous involvement of the oesophagus is rare. Carr and Spain (1942) reported macroscopic lesions of tuberculosis in the oesophagus in $0.14 \%$ of 18049 tuberculous patients at necropsy. In most cases oesophageal tuberculosis is secondary to tuberculous lesions 


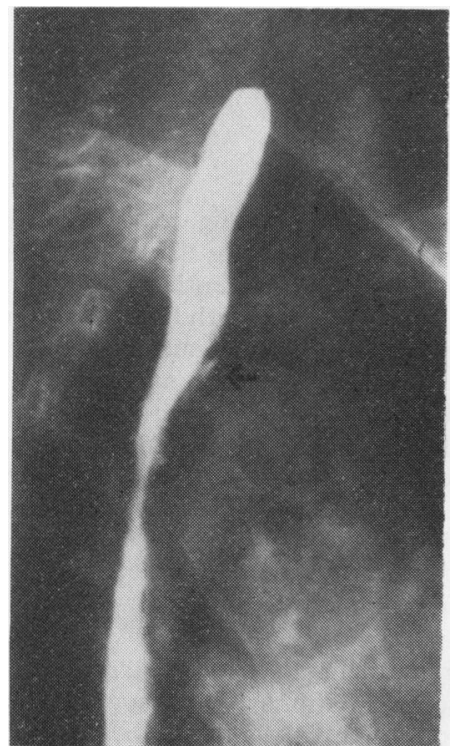

Fig 2 Barium swallow showing ulcer in upper third of oesophagus, July 1977.

elsewhere, such as pulmonary or laryngeal disease or tuberculous involvement of mediastinal glands. Less often it may be secondary to Pott's disease or the result of haematogenous dissemination in miliary tuberculosis (Pelemans and Hellemans, 1974). Primary tuberculosis of the oesophagus is very rare but a few cases have been reported (Audouin and Poulain, 1950, Baron et al, 1961; Fahmy et al, 1969; Cornet et al, 1973).

In our patient, although there was no evidence of pulmonary or mediastinal involvement on the initial chest radiographs, the appearance of tuberculous glands in the neck, the subsequent pleural effusion, and the breaking down mass in the oesophageal wall strongly suggest that the oesophageal involvement was secondary to tuberculosis affecting mediastinal glands.

\section{References}

Audouin, J, and Poulain, J (1950). Tuberculose sténosante de l'oesophage d'apparence primitive, guérie par l'oesophagectomie. Archives Francaises des

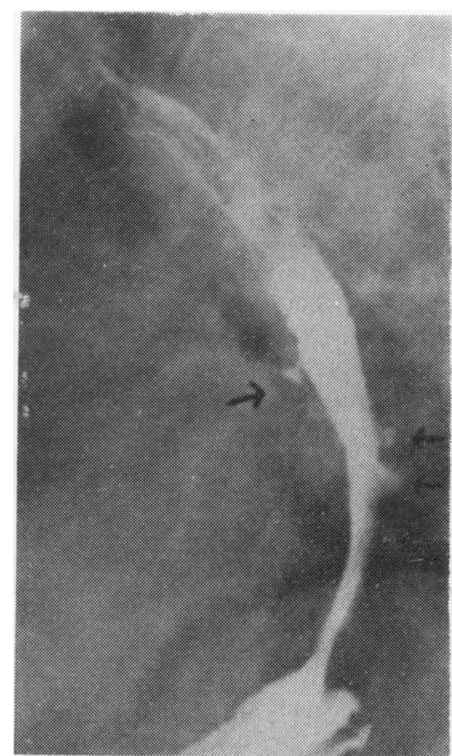

Fig 3 Barium swallow showing a healed ulcer, irregular outline, and traction diverticula, November 1977.

Maladies de l'Appareil Digestif et de la Nutrition, 39, 231-236.

Baron, F, Venisse, C, and Legal, G (1961). A propos d'un cas de tuberculose primitive de l'oesophage. Annals d'Otolaryngologie, 78, 142-145.

Carr, D T, and Spain, D M (1942). Tuberculosis in a carcinoma of the esophagus. American Review of Tuberculosis, 46, 346-349.

Cornet, A, Choubrac, P, Barbier, J Ph, François, C, and Cornet, F (1973). Tuberculose de l'oesophage. Annals de Gastroenterologie et d'Hépatologie, 9, 339-348.

Fahmy, A R, Guindi, R, and Farid, A (1969). Tuberculosis of the esophagus. Thorax, 24, 254-256.

Pelemans, W, and Hellemans, J (1974). Tuberculosis of the esophagus. In Diseases of the Esophagus, edited by $G$ Vantrappen and J Hellemans, pp 553555. Springer-Verlag, Berlin.

Requests for reprints to: Dr J Rubiés-Prat, Department of Internal Medicine, Ciudad Sanitaria Seguridad Social, Av Valle Hebrón s/n, Barcelona 35. 